\title{
Teleseismic magnitude relations
}

\author{
Markus Bàth (*)
}

Received on September 24 th, 1977.

RiAssunto - Le raccomandazioni fatte a Zurigo nel 1967, sulla determinazione della magnitudo, hanno avuto diverse notevoli applicazioni usando valide seri: complete di valori determinati dalla magnitudo, cominciando anzitutto a servirsi di quelli raccolti dal bollettino sismico di Uppsala. In questo modo sono state correlate le magnitudo $(m)$ delle onde spaziali e quelle $(M)$ delle onde superficiali, le une rispetto alle altre, per 12 diverse regioni sismiche diffuse e conosciute in tutto il mondo. Si sono trovate le correzioni di $M$ relative a tutte le profondità focali. Sono state sviluppate formule che permettono il calcolo di $M$ anche dalla componente verticale dei sismograli a lungo periodo. Sono state messe a confronto le magnitudo delle onde spaziali ottenute su registrazioni ad alta e bassa banda di sismograft a breve periodo e ne sono state dedotte le relazioni corrispondenti.

Sono state fatte applicazioni sia ad esplosioni nucleari sotterranee sia a terremoti. Vengono inoltre valutate le possibilità di discriminare, servendosi della magnitudo, le esplosioni dai terremoti, come pure - sempre dalla magnitudo di valutare quanto esplosivo sia stato usato. Per quanto riguarda $i$ terremoti, vengono studiate le relazioni fra le magnitudo delle scosse principali e quelle delle repliche più forti. Per determinazioni più omogenee della magnitudo si suggerisce di istituire una rete mondiale di stazioni che possa fornire il necessario sistema d'informazioni.

SUmmary - Using available sets of magnitude determmations, primarily from Uppsala seismological bulletin, various extensions are made of the Zurich magnitude recommendations of 1967. Thus, body-wave magnitude $(m)$ and surface-wave magnitudes $(M)$ are related to each other for 12 different earthquake regions as well as world-wide. Depth corrections for $M$ are derived for all focal depths. Formulas are developed which permit calculation of $M$ also from vertical component long-period seismographs. Body-wave magnitudes from broad-

$\left({ }^{*}\right)$ Seismological Institute. Box 517. S-751 20 Uppsala. Sweden. 
band and narrow-band short-period seismographs ate compared and relations deduced. Applications are made both to underground nuclear explosions and to earthquakes. The possibilities of explosion-earthquake discrimination on the basis of magnitudes are examined, as well as the determination of explosive yield from magnitudes. For earthquakes, relations between magnitudes of main earthquakes and largest aftershocks are investigated. A world-wide station network for more homogeneous magnitude determinations is suggested in order to provide the necessary reference system.

\section{Introduction.}

At the assembly of the International Association of Seismology and Physics of the Earth's Interior (IASPEI) in Zurich in 1967, certain recommendations were adopted in order to create better homogeneity in seismic magnitude calculations. In the past decade, the Zurich recommendations have had both a stabilizing and a stimulating effect on magnitude calculations and related research. In the past years, numerous sets of magnitude determinations have been collected which call for more detailed study, both in order to revise earlier magnitude relations and to make any possible extensions. In general, relations between body-wave magnitudes $(m)$ and surface-wave magnitudes $(M)$ have hitherto been given as world-wide averages, a notable exception being Bormann and Wylegalla (1975). It now becomes evident that significant regional deviations exist. Likewise, the focal-depth correction of surface-wave magnitudes $(M)$, hitherto only known approximately for focal depths less than $100 \mathrm{~km}$, could now be derived for any focal depth. The differences between body-wave magnitudes $(m)$ as derived from different instruments, have also called for more detailed study. There are numerous applications of the magnitude concept which can be subjected to further investigation and possible refinement, such as for discrimination between explosions and earthquakes, for determination of explosive yield, and in the study of aftershock sequences.

Problems as those just mentioned and related ones, together with the present existence of homogeneous sets of magnitude determinations, prompted the present study. In this paper, I shall attempt to contribute to the solution of the problems mentioned, using primarly observational material from the Swedish seismograph network. Improved and extended magnitude relations will contribute to our knowledge of the underlying causes, i. e. both source and path properties. Naturally, not all magnitude 
problems have been dealt with. For example, the calibrating functions distance and depth dependence, attenuation) have been assumed as given in the Zurich recommendations. This will not affect the methods used, nor the main results as these are primarily based on relative measurements.

In the past decade, numercus valuable papers have appeared in the literature with close relations to one section or another in the following. These papers would rather deserve a special detailed review than brief mentioning here. From such considerations, I have restricted the present paper essentially to my own contributions and limited the references accordingly. To a certain extent, the present paper follows up and extends results derived eariier by me, especiaily in Båth (1956).

2. LIST OF SYMBOLS AND ABBREVIATIONS.

$a, b, a^{\prime}, b^{\prime} \quad$ parameters in derived solutions;

$A \quad$ ground amplitude, microns;

$A_{P}, A_{R} \quad$ ground amplitude of $P$ wave and of Rayleigh wave, respectively, microns;

B Benioff instrument, used as subscript;

C calculated, used as subscript;

D standard deviation (subscripts are used to specify which quantity the deviation refers to, e. g. $D_{m}, D_{M}$ );

$E \quad$ seismic wave energy, ergs;

$E, N, Z$ east-west, north-south and vertical components, respectively, used as subscripts;

$g \quad$ depth parameter in the calculation of $M$;

$G \quad$ Grenet instrument, used as subscript;

h focal depth, $\mathrm{km}$;

$H \quad$ horizontal component, used as subscript;

$\log$. decadic logarithm;

$L \quad$ wavelength, $\mathrm{km}$;

$m$ body-wave magnitude, average of UPP and KIR;

$m$ (US) body-wave magnitude, as given by NEIS;

$M$ surface-wave magnitude, average of UPP and KIR; 
$M_{1} \quad$ surface-wave magnitude of largest aftershock, average of UPP and KIR

$N$ number of observations or pairs of observations;

$o \quad$ observed, used as subscript;

$p \quad$ perpendicular distance of a straight line from the origin;

$q(\Delta, h) \quad$ calibrating function for $m$;

$T \quad$ wave period, sec;

$x, y \quad$ Cartesian coordinates;

$Y \quad$ yield of underground nuclear explosion, kt;

$\alpha \quad$ angle between abscissa and normal to straight line;

$\gamma \quad$ seismic efficiency;

$\Delta \quad$ epicentral distance, degrees;

ISC International Seismological Centre;

KIR Kiruna, Sweden: $67^{0} 50.4^{\prime} \mathrm{N}, 20^{\circ} 25.0^{\prime} \mathrm{E}$;

NEIS National Earthquake Information Service (U. S. Geological Survey);

NTS Nevada Test Site;

PAL Palisades, New York, U. S. A.: $41^{0} 00.4^{\prime} \mathrm{N}, 73^{0} 54.5^{\prime} \mathrm{W}$;

UME Umeã (WWSSN), Sweden: $63^{\circ} 48.9^{\prime} \mathrm{N}, 20^{\circ} 14.2^{\prime} \mathrm{E}$;

UPP Uppsala, Sweden: $59^{\circ} 51.5^{\prime} \mathrm{N}, 17^{\circ} 37.6^{\prime} \mathrm{E}$.

\section{Methods.}

In short, the Zurich recommendations can be stated as follows (cf. Bâth, 1969, p. 131):

Body-wave magnitudes $m$ are calculated for $P, P P, S$ from:

$$
\begin{gathered}
m=\log (A / T)+q(\Delta, h) \\
\Delta \geq 16^{0}
\end{gathered}
$$

where $q(\Delta, h)$ is the calibrating function after Gutenberg and Richter 1956).

Surface-wave magnitudes $M$ are calculated for horizontal-component surface waves (Rayleigh) from: 


$$
\begin{gathered}
M=\log \left(A_{H} / T_{H}\right)+1.66 \log \Delta+3.3 \\
T_{H}=10-30 \mathrm{sec}, \Delta \geq 20^{\circ}
\end{gathered}
$$

i. e. the so-called Moscow-Prague formula (Vanek et al., 1962).

The calculations in this paper will essentially consists in relating various quantities two and two, like $m$ and $M$. In graphical plots of such quantities, generally quite a large scatter is observed resulting in oval-shaped point clouds. This fact has been of dominating influence on our methods of dealing with the data. As a general notation of the two quantities to be related we use $y$ (ordinate) and $x$ (abscissa). With $a$ and $b$ as constants, we can in our cases then best describe the relation between $y$ and $x$ as a linear equation:

$$
y=a x+b .
$$

Putting $a=1$, i. e. assuming a constant difference $b$ between $y$ and $x$, proves generally not to be an acceptable procedure. On the other hand, it proves unnecessary to include second-degree terms in $x$. Actual tests on our observational material demonstrate that the scatter is such that a seccnd-degree polynomial on the right-hand side of equation [3] does not improve the accuracy.

With the straigh-line representation as in equation [3], there are three different possibilities to place such a line to fit a given point cloud:

(1) Regression of $y$ on $x$, which we denote as $y \rightarrow x$. This is the common procedure, which by a least squares solution, i. e. minimizing the sum of the squares of the vertical distances from individual points to the line, yields the following expressions for the constants $a$ and $b$ :

$$
\begin{aligned}
& a=\frac{\sum x \Sigma y / N-\Sigma x y}{(\Sigma x)^{2} / N-\Sigma x^{2}} \\
& b=(\Sigma y-a \Sigma x) / N
\end{aligned}
$$

where the sums are extended over all points, i. e. all pairs of values $y, x$.

(2) Regression of $x$ on $y$, which we denote as $x \rightarrow y$. The same procedure applied to the horizontal distances (parallel to the $x$-axis), 
leads to a solution of the following equation:

$$
x=a^{\prime} y+b^{\prime} .
$$

(3) Major axis solution or orthogonal regression, denoted $x \leftrightarrow y$, reproduces the majcr axis of the point cloud and is obtained by minimizing the sum of the squares of the distances perpendicular to the line. A least squares procedure leads to the following solution for the major axis:

$$
x \cos \alpha+y \sin \alpha-p=0
$$

with

$$
\begin{gathered}
\tan 2 \alpha=\frac{2(\Sigma x y-\Sigma x \Sigma y / N)}{\left[\Sigma x^{2}-(\Sigma x)^{2} / N\right]-\left[\Sigma y^{2}-(\Sigma y)^{2} / N\right]} \\
p=(\cos \alpha \Sigma x+\sin \alpha \Sigma y) / N .
\end{gathered}
$$

In the following we have applied all three methods, as they have each their merits. Methods (1) and (2) are mainly justified for computational purposes, providing the minimum error of the required quantity. Thus, the regression $y \rightarrow x$ of the form of equation [3], is used for calculating $y$ for a given $x$. Conversely the regression $x \rightarrow y$, i. e. equation [5], is used for calculating $x$ for a given $y$. On the other hand, the major axis solution, which best represents the point cloud as such, is to be preferred for physical reasons. While the major axis solution can be inverted, i. e. solved for either $x$ or $y$, an inversion is generally not permitted for the regressions. The relations between the three solutions (1), (2) and (3) depend on the shape and slope of the point cloud. If the point cloud is very narrow, approaching a straight line, the three solutions will be closely similar, whereas they diverge more and more for a broad oval-shaped point cloud. The slope will also influence, an extreme case being a horizontal point cloud, for which the regression $y \rightarrow x$ and the major axis solution will agree, whereas the regression $x \rightarrow y$ will be at righ angle to the other two. In general, the three sclutions show best agreement with each other in the central parts of the point c'ouds and they may diverge strongly lowards their extremities.

The scatter as observed in the point clouds is not due to measuring crrors but to the circumstance that quite a number of factors influences the measurements, such as source and path properties. To correct each reading for such influences would be a practically hopeless task. 
Instead we apply statistical averaging and assume that by the mentioned straight-line fittings to a sufficient sample, the various effects will cancel each other. In the regressions, evidently one variable is assumed to be correct and the deviation is assigned exclusively to the other variable, whereas in the major axis solution both variables are assumed to exhibit deviations.

In earthquake statistical research, where homogeneous magnitude series over long periods of time are needed, relations of the types mentioned will have to be used. Therefore, a good rule for seismograph stations replacing old equipment by new one is to have both running in parallel for such a long time as to permit reliable comparisons. From overlapping series of records, it is possible to relate one magnitude to another magnitude (from a different instrument or a different station, etc.), which will permit reductions of long observational series to one homogeneous magnitude scale. An example of such calculations can be found in a paper by Alsan et al. (1975). It is then important to use the proper regressions, also to use only direct or immediate relations and to avoid the consecutive use of intermediary relations. The latter will rapidly lead to accumulation of errors and becomes increasingly unreliable.

The observational scatter is in each case expressed as the standard deviation of the respective formulas. For the regression solutions the standard deviations $D_{y}$ and $D_{x}$ are calculated, respectively, while in the case of majcr axis solutions, we give three standard deviations, i. e. in addition to $D_{y}$ and $D_{x}$ also $D$, which refers to the perpendicular distances from the points to the line. It is obtained from the following equation:

$$
D=D_{y} \cos \left(\alpha-90^{\circ}\right)=D_{x} \sin \left(\alpha-90^{\circ}\right)
$$

In dealing with observations of this kind, it is important to test that the sample used is large enough to be representative. An efficient method was found to use successively $5,10,15,20, \ldots$ observations, until the whole set is used up, and to calculate the parameters in each case. Plotting the respective parameters against the number of observations, we find that after some initial, sometimes large oscillations, the parameters stay within the limits corresponding to the standard deviation of the total sample. The number of observations at the point where the parameters begin to stay within the final limits, is the minimum number of observations needed for a representative sample. 
4. Relations betweEn $m$ ANd $M$.

The observational material consists of magnitudes published in the Uppsala monthly seismological buletin for the period from January 1970 to April 1975. The body-wave magnitudes $m$ are averages of short-period vertical-component $P$ from Uppsala and Kiruna (Grenet), and the surface-wave magnitudes $M$ are averages of long-period measurements from Uppsala (Benoff) and Kiruna (Galitzin). These magnitudes ought to be rather homogeneous, having all been measured and calculately by the present author. The material has been divided into 12 regions according to epicenter location, as listed in Table 1. To avoid the influence of local depth $h$ on $M$, only earthquakes with $h \leq 50 \mathrm{~km}$ are used in the present section.

The regressions and the major axis solutions are summarized in Table 2 for each region and for the total material, together with respective standard deviations. We note that the major axis solution for the total material, that is:

$$
m=0.55 M+2.94
$$

agrces a'most exactly with the one included in the Zurich recommendations:

$$
m=0.56 M+2.9
$$

An interesing result is that the parameters $a$ and $b$ are strongly connected to each other, as evidenced by their correlation coefficients and regressions, summarized in Table 3. Geometrically, this means that all the lines in each group intersect in nearly one and the same point, but have difierent slopes. Without less of accuracy, it is thus possible to substitute these regressions into those between $m$ and $M$, with the results given in the last column of Table 3. This means that just one parameter, instead of two, is enough to define each relation bctween $m$ and $M$. This parameter bears the characteristics of a regional magnitude parameter. It is probably a complicated function of source and path properties, but it does not show any obvious dependence on $M$.

Even though calculated magnitudes agree between the different regions within error limits, at least in the central parts of the point 
TABLE 1.

Observational material for $m, M$ and $m$ (US).

\begin{tabular}{|c|c|c|c|c|c|c|c|}
\hline \multirow{2}{*}{$\begin{array}{l}\text { Earthquake } \\
\text { region }\end{array}$} & \multirow{2}{*}{$\begin{array}{l}\text { Geographical } \\
\text { area }\end{array}$} & \multicolumn{3}{|c|}{ Number of earthquakes } & \multicolumn{3}{|c|}{ Ranges covered } \\
\hline & & $h \leq 50$ & $h>50$ & Total & $m$ & $M$ & $m(U S)$ \\
\hline 1 & Aleutians. Unimak & 45 & 11 & 56 & $5.8-7.1$ & $5.0-7.1$ & $5.0-6.3$ \\
\hline 2 & $\begin{array}{l}\text { Alaska, Kodiak. Queen Elisabeth, Queen Chat lotte, Vancouver, } \\
\text { Oregon, Calilornia, Idaho }\end{array}$ & 37 & 6 & 43 & $5.5-7.1$ & $5.0-7.9$ & $4.9-6.5$ \\
\hline 3 & $\begin{array}{l}\text { Eastern Pacific, Mexico, Guatemala, Nicaragua, Costa Rica, Panama, } \\
\text { Haiti, Dominican Republic, Leeward Istlands, Virgin Islands, } \\
\text { Colombia, Venezucla. Ecuador, Peru. Chile, Argentina }\end{array}$ & 33 & 17 & 50 & $5.6-7.5$ & $5.1-7.8$ & $5.4-7.1$ \\
\hline 4 & Japan, Ryukyu & 87 & 18 & 105 & $5.7-7.6$ & $5.0-8.0$ & $5.0-6.6$ \\
\hline 5 & Kurile Islands, Okhotsk Sea, Sakhalin & 64 & 14 & 78 & $5.7-7.5$ & $5.0-7.8$ & $5.0-6.6$ \\
\hline 6 & Kamchatka, Komandorsky & 27 & 6 & 33 & $5.8-7.5$ & $4.9-7.8$ & $4.8-6.3$ \\
\hline 7 & $\begin{array}{l}\text { Formosa, Luzon, Mindanao, Mindoro, Samar, Leyte, Negros, } \\
\text { Panay, Bonin, Mariana }\end{array}$ & 68 & 34 & 102 & $5.6-7.7$ & $5.3-8.5$ & $4.8-6.4$ \\
\hline 8 & $\begin{array}{l}\text { Bengal Bay, Andaman, Nicobar, Sumatra, Java, Celebes, Sunda, } \\
\text { lialmahera. Talaud. Timor, Banda. Sumbawa, Tanimbar, Sumba, } \\
\text { Aroe, Molucca, Ceram, New Guinea, Solomon, New Britain, New } \\
\text { Ireland }\end{array}$ & 44 & 25 & 69 & $5.7-7.7$ & $5.1-8.2$ & $5.1-7.3$ \\
\hline 9 & Burma, Nepal, India, Pakistan, Afghanistan, Hindu Kush, Iran & 36 & 10 & 46 & $5.5-7.5$ & $5.0-7.1$ & $4.9-6.5$ \\
\hline 10 & $\begin{array}{l}\text { Caucasus. Turkey, Crete, Aegean Sea, Greece, Albania, Yugoslavia, } \\
\text { lialy, Austria, France, Alger }\end{array}$ & 69 & 4 & 73 & $5.0-6.9$ & $4.5-7.4$ & $4.5-6.0$ \\
\hline 11 & $\begin{array}{l}\text { China, Yunnan, Szechwan, Sinkiang, Tien-Shan, Kashmir, Alma-Ata, } \\
\text { Tibet, USSR-Mongolia, Tadzhik, Kirghiz, Uzbek, Baikal, Siberia, } \\
\text { East Russia }\end{array}$ & 93 & 5 & 98 & $5.5-7.2$ & $4.9-7.8$ & $4.8-6.5$ \\
\hline 12 & $\begin{array}{l}\text { Arctic, Svalbard, Greenland Sea, Norwegian Sea, Jan Mayen, } \\
\text { Iceland. Ascension, North and South Atlantic }\end{array}$ & 49 & 0 & 49 & $4.8-7.2$ & $4.2-7.1$ & $4.3-6.3$ \\
\hline & Scattered location & 17 & 0 & 17 & $5.7-6.5$ & $5.1-6.8$ & $5.0-6.2$ \\
\hline Total & & 669 & 150 & 819 & $4.8-7.7$ & $4.2-8.5$ & $4.3-7.3$ \\
\hline
\end{tabular}


TABLE 2 .

Relations between $m$ and $M$ for $h \leq 50 \mathrm{~km}$.

\begin{tabular}{|c|c|c|c|c|c|c|c|c|c|c|c|c|c|}
\hline \multirow{3}{*}{$\begin{array}{l}\text { Earthquake } \\
\text { region }\end{array}$} & \multicolumn{6}{|c|}{ Regressions } & \multicolumn{7}{|c|}{ Major axis solutions } \\
\hline & \multicolumn{3}{|c|}{$m=a M+b$} & \multicolumn{3}{|c|}{$M=a^{\prime} m+b^{\prime}$} & \multicolumn{3}{|c|}{$m=a M+b$} & \multicolumn{4}{|c|}{$M=a^{\prime} m+b^{\prime}$} \\
\hline & $a$ & $b$ & $\pm D_{m}$ & $a^{\prime}$ & $b^{\prime}$ & $\pm D_{M}$ & $a$ & $b$ & $\pm D_{m}$ & $a^{\prime}$ & $b^{\prime}$ & $\pm D_{M}$ & $\pm D$ \\
\hline 1 & 0.22 & 5.10 & 0.29 & 0.61 & $1.8 j$ & 0.50 & 0.31 & 4.59 & 0.30 & 3.26 & -14.94 & 0.98 & 0.29 \\
\hline 2 & 0.26 & 4.78 & 0.34 & 0.75 & 1.15 & 0.62 & 0.34 & 4.26 & 0.36 & 2.91 & -12.40 & 1.06 & 0.34 \\
\hline 3 & 0.39 & 3.98 & 0.25 & 1.48 & -5.24 & 0.51 & 0.43 & 3.72 & 0.26 & 2.30 & -8.55 & 0.60 & 0.24 \\
\hline 4 & 0.37 & 4.04 & 0.27 & 0.88 & 0.49 & 0.43 & 0.49 & 3.35 & 0.28 & 2.06 & -6.89 & 0.57 & 0.25 \\
\hline 5 & 0.33 & $4.3 !$ & 0.23 & 1.32 & -2.38 & 0.45 & 0.38 & 4.03 & 0.23 & 2.63 & -10.59 & 0.60 & 0.21 \\
\hline 6 & 0.42 & 4.00 & 0.29 & 1.12 & -1.47 & 0.45 & 0.50 & 3.53 & 0.29 & 1.98 & -6.99 & 0.57 & 0.26 \\
\hline 7 & 0.43 & 3.69 & 0.27 & 1.43 & -2.84 & 0.48 & 0.47 & 3.41 & 0.27 & 2.12 & -7.22 & 0.57 & 0.24 \\
\hline 8 & 0.53 & 3.18 & 0.30 & 1.17 & -1.35 & 0.45 & 0.61 & 2.68 & 0.30 & 1.63 & -4.38 & 0.49 & 0.26 \\
\hline 9 & 0.45 & 3.52 & 0.24 & 1.14 & -1.17 & 0.39 & $0.5 j$ & 3.04 & 0.25 & 1.87 & -5.69 & 0.45 & 0.22 \\
\hline 10 & 0.56 & 2.73 & 0.27 & 1.14 & -1.13 & 0.39 & 0.64 & 2.27 & 0.28 & 1.56 & -3.54 & 0.43 & 0.24 \\
\hline 11 & 0.39 & 3.82 & 0.26 & 1.38 & -2.62 & 0.50 & 0.44 & 3.54 & 0.26 & 2.28 & -8.05 & 0.61 & 0.25 \\
\hline 12 & 0.61 & 2.53 & 0.29 & 1.15 & -1.30 & 0.40 & 0.68 & 2.12 & 0.30 & 1.46 & -3.11 & 0.44 & 0.25 \\
\hline Total & 0.47 & 3.41 & 0.31 & 1.15 & -1.28 & 0.48 & 0.55 & 2.94 & 0.32 & 1.80 & -5.29 & 0.57 & 0.28 \\
\hline $\begin{array}{l}\text { Nuclear } \\
\text { explosions }\end{array}$ & 0.19 & 5.66 & 0.22 & 0.80 & 0.18 & 0.46 & 0.24 & $5.4 !$ & 0.22 & 4.20 & -22.69 & 0.95 & 0.21 \\
\hline
\end{tabular}


TABLE 3.

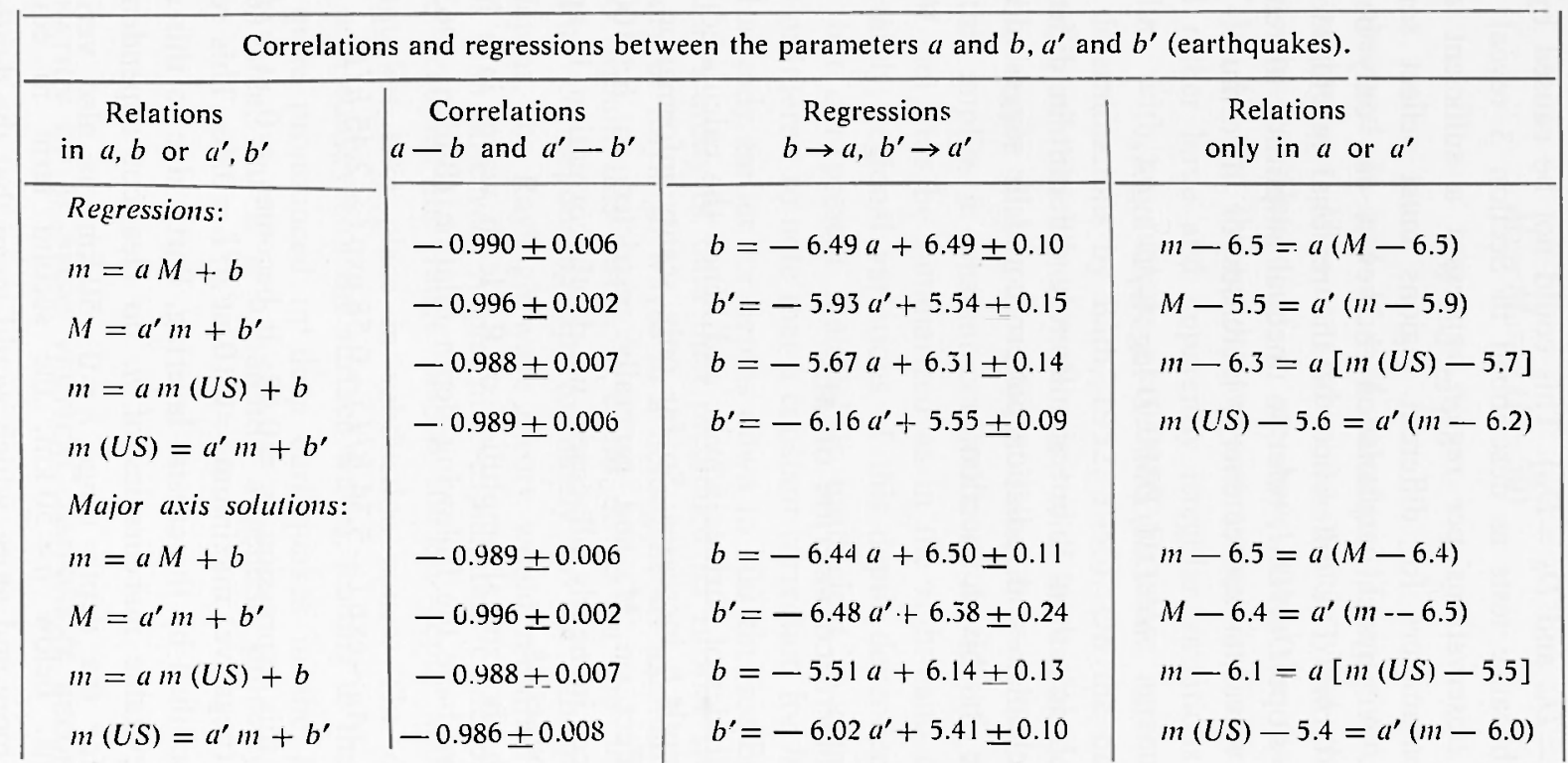


clouds, the parameters $a$ and $b$ differ significantly from region to region $\left(D_{b}=D_{m}\right.$ and $\left.D_{b^{\prime}}=D_{11}\right)$. This could not be caused by insufficient sampling, because tests as describbed in Section 3 reveal that already 20 to 30 observations per region represent a sufficient sample. The different parameters for different regions must reflect some physical differences. A physical explanation, however, can only be formulated in general terms. The differences of the regional magnitude parameters $a$,i. e. the slope $D m / D M$, refer to unequal amplitude increase of $P$ and of surface waves, as source energy increases, or in formula:

$$
a=D M / D M=D \log A_{\Gamma} / D \log A_{R}
$$

This ratio is less than 1 , but significantly different in different regions. Scurce mechanism and radiation pattern could be suggested as factors of significance in this connection.

\section{Focal depti CorRection of $M$.}

Amplitudes of surface waves, and hence the calculated $M$, decrease as focal depth $h$ increases. So far only scanty information is available on this effect on $M$, and generally restricted to $h \leq 100 \mathrm{~km}$. As a consequence, in nearly all cases, no depth correction is applied to $M$ given in bul!etins.

For the horizcntal amplitude of Rayleigh waves in a homogeneous medium, we have the following depth relation (Bullen, 1963, p. 90):

$$
A_{l l} \sim \exp (-5.34 h / L)-0.58 \exp (-2.45 h / L) .
$$

For $h=0$, this expression is $=0.42$; it becomes $=0$ at $h / L=0.19$ and attains its (negative) maximum $=0.10$ at $h / L=0.46$. This result may be strongly modificd by the crustal layering. Partly due to this effect, partly due to inevitable inaccuracies of $h$, no clear-cut dependence is to be expccted for the depth range $h=0-50 \mathrm{~km}$, as also verified by our cbservations. Below $h=50 \mathrm{~km}$, the second term in equation [11] dominates more and more, which would mean that the depth dependence would be more purely exponential. The magnitudes, i. e. logarithms of amplitudes, could thus be expected to vary linearly with $h$ for $h>50 \mathrm{~km}$. 
The depth effect on $M$ is calculated from the following relations:

$$
\begin{gathered}
M_{c}-M_{o}=g(h-50) \\
M_{c}=a^{\prime} m+b^{\prime}
\end{gathered}
$$

where $M_{o}=$ observed $M$ and $M_{c}=M$ calculated from given $m$ using the regional regressions $M \rightarrow m$ (Table 2,) which yield the highest accuracy. For the calculation of $g$ we have used the material for $h>50 \mathrm{~km}$ (Table 1), and the results are summarized in Table 4 .

We find rather large and apparently irregular variations of $g$ for $50<h<100 \mathrm{~km}$, with an average $g=0.0088$ (in close agreement with some earlier determinations by Bath, 1952, 1956). On the other hand, for $h>100 \mathrm{~km}, g$ exhibits a steady decrease with increasing depth, with the remarkable result that $g(h-50)$ is constant $=0.38 \pm 0.03$. For $h>100 \mathrm{~km}$, this implies a constant correction to $M$. Depth corrections to apply to $M$ can thus be summarized as in the right-hand column of Table 4. Certainly, regional variations of this depth dependence are to be expected, but our present material is insufficient to establish this reliably. It is of interest to note that a constant correction for $h \geq 100 \mathrm{~km}$ was cbtained already earlier for depths down to $300 \mathrm{~km}$ (see Bath, 1952 , fig. 2), but that scarcity of data then precluded its further study.

The theory of Rayleigh waves in a homogeneous medium is clearly insufficient to explain this result. It could do so for the depth range $50<h<100 \mathrm{~km}$, corresponding approximately to the lithosphere. But for greater depths, the Rayleigh wave theory would require far greater $M$ corrections than observed. A plausible explanation could be that the asthenosphere occupies the range below $100 \mathrm{~km}$ depth and that the deeper earthquakes take place in subduction zones. The downgoing slab may act as a conveyer of the surface waves, leading to the observed effect. It is quite pronounced in deep earthquakes in the Japan and Bonin Islands area, but it is apparently a general property of deep earthquakes.

\section{Determination of $M$ from vertical-component records.}

Where the Moscow-Prague formula for $M$, equation [2], was developed only for the horizontal component of surface waves, it is 
TABLE 4.

\begin{tabular}{|c|c|c|c|c|c|c|}
\hline \multicolumn{7}{|c|}{ Depth dependence of surface-wave magnitudes $M$. } \\
\hline \multicolumn{2}{|c|}{$\begin{array}{l}\text { Focal depth } h \\
\text { Range Average }\end{array}$} & \multirow{2}{*}{$\mid \begin{array}{c}\text { Number of } \\
\text { observations }\end{array}$} & \multirow{2}{*}{$\frac{\begin{array}{c}\text { Depth factor } \\
g\end{array}}{0.0084}$} & \multirow{2}{*}{$\frac{g(h-50)}{0.0840}$} & \multicolumn{2}{|c|}{$\begin{array}{l}\text { Resulting depth corrections } \\
\text { Depth } h \text { Correction } \delta_{M}\end{array}$} \\
\hline $50-75$ & 60 & & & & $0-50$ & 0.0 \\
\hline $50-100$ & 66 & 95 & 0.0088 & 0.1408 & 60 & +0.1 \\
\hline $70-100$ & 87 & 20 & 0.0104 & 0.3848 & 70 & +0.2 \\
\hline $101-1501$ & 131 & 24 & 0.0045 & 0.3645 & 80 & +0.3 \\
\hline $151-2001$ & 174 & 7 & 0.0029 & 0.3596 & 90 & +0.4 \\
\hline $201-3002$ & 235 & 6 & 0.0023 & 0.4255 & 100 & +0.4 \\
\hline $301-4504$ & 403 & $4\left(^{(1)}\right.$ & 0.0010 & 0.3530 & 100 & +0.4 \\
\hline $451-6005$ & 553 & 7 & 0.0007 & 0.3521 & & \\
\hline $601-7006$ & 632 & 5 & 0.0007 & 0.4074 & & \\
\hline
\end{tabular}

(1) Two anomalous cases exluded. 
obvious that it would be convenient to have a corresponding formula for the vertical component. Partly, this would need measuring only one record instead of two for the $M$ calculation, partly and above all, the vertical component shows pure Rayleigh waves with no interference of Love waves as the horizontal components. The problem can be stated as to develop a formula for the vertical component giving the closest possible fit in $M$ tc the horizontal component, equation [2]. This reduces to determining the following regression:

$$
\log \left(A_{H} / T_{H}\right)=a \log \left(A_{Z} / T_{Z}\right)+b
$$

where we admit a parameter $a \neq 1$ on the basis of earlier experience from Pasadena (Batth, 1952). On the other hand, we are assuming the same distance dependence (geometrical spreading, attenuation, dispersion) for the vertical as for the horizontal component. The resulting horizontal amplitude is in each case calculated as the vectorial sum of $A_{E}$ and $A_{N}$, that is:

$$
A_{H}=\left(A^{2}{ }_{E}+A^{2}\right)^{1 / 2} .
$$

This will include also Love waves in $A_{H}$, but this effect is found to be relatively insignificant in the total material. $T_{H}$ is taken as the average of $T_{E}$ and $T_{N}$.

Our observational material is reviewed in Table 5. In this case I have also included a set of long-period measurements which I made on Palisades records (Columbia University seismographs) on a visit in 1952. The depth range has been restricted to $h \leq 50 \mathrm{~km}$, even though the relations between $H$ and $Z$ components are expected to be valid for any depth. Least squares solution of equation [13] yields the following results:

Uppsala: $\quad \log \left(A_{n} / T_{n}\right)=0.97 \log \left(A_{Z} / T_{Z}\right)-0.05 \pm 0.14$

Kiruna: $\quad \log \left(A_{H} / T_{l l}\right)=0.99 \log \left(A_{Z} / T_{Z}\right)+0.18 \pm 0.14$

Palisades: $\quad \log \left(A_{I I} / T_{I I}\right)=0.99 \log \left(A_{Z} / T_{Z}\right)-0.02 \pm 0.12$.

In these equations the standard deviations refer to each station separately, i. e. they are the deviations of $M_{Z}$ from $M_{\| \prime}$ for Uppsala, Kiruna 
TABLE 5.

Review of observational material for Sections 6 to 9 .

\begin{tabular}{|c|c|c|c|c|c|c|}
\hline Type of observation & $\begin{array}{l}\text { Number of } \\
\text { observations }\end{array}$ & Years & Regions & $\begin{array}{c}\text { Focal depth } \\
\mathrm{km}\end{array}$ & Magnitude ranges & Other ranges \\
\hline $\begin{array}{l}\text { Vertical component } \\
\text { (Section 6) }\end{array}$ & $\begin{array}{l}249 \text { (UPP) } \\
245 \text { (KIR; } \\
91 \text { (PAL) }\end{array}$ & \begin{tabular}{|l|}
$1972-75$ \\
$1972-73$ \\
$1950-52$
\end{tabular} & $\begin{array}{l}\text { All regions } \\
\text { (earthquakes) }\end{array}$ & $\leq 50$ & $\begin{array}{l}M: 4.5-8.0 \text { (UPP) } \\
M: 4.5-8.0(\mathrm{KIR}) \\
M: 5.8-8.0(\mathrm{PAL})\end{array}$ & $\begin{aligned} A_{H}: & 0.6-900 \mathrm{micr}(\mathrm{LPP}) \\
& 0.7-1190 \mathrm{micr} \text { (KIR) } \\
& 0.4-110 \mathrm{micr} \text { (PAL) } \\
A_{Z}: & 0.5-610 \mathrm{micr} \text { (UPP) } \\
& 0.4-810 \mathrm{micr} \text { (KIR) } \\
& 0.5-100 \mathrm{micr} \text { (PAL) }\end{aligned}$ \\
\hline $\begin{array}{l}\text { Relations for } m \text { (UME) } \\
\text { (Section 7) }\end{array}$ & 159 (UME) & $\begin{array}{l}1966 \\
\text { May-Aug }\end{array}$ & $\begin{array}{l}\text { All regions } \\
\text { (earthquakes) }\end{array}$ & Any depth & $\begin{array}{l}m_{B}: 4.4-7.0 \\
m_{G}: 4.7-7.4 \\
\text { (approx.) }\end{array}$ & $\begin{array}{l}A_{B}: 0.01-1.1 \mathrm{micr} \\
A_{G}: 0.02-2.8 \mathrm{micr}\end{array}$ \\
\hline $\begin{array}{l}\text { Underground Explosions } \\
\text { (Section 8): } \\
\text { Magnitude relations } \\
\text { Yield relations }\end{array}$ & $\begin{array}{l}25 \text { (UPP, KIR) } \\
14 \text { (UPP, KIR) }\end{array}$ & $1962-73$ & $\begin{array}{l}\text { Nevada, Aleutians, } \\
\text { Semipalatinsk, } \\
\text { Novaya Zemlya, } \\
\text { Caspian Sea area } \\
\text { Nevada }\end{array}$ & $0-1.4$ & $\begin{array}{l}m: 6.4-7.2 \\
M: 4.5-6.4 \\
m(\text { US }): 5.5-6.9 \\
m: 5.8-6.5\end{array}$ & $Y: 36-1200 \mathrm{kt}$ \\
\hline $\begin{array}{l}\text { Aftershocks } \\
\text { (Section 9) }\end{array}$ & 116 (UPP, KIR) & 1968.75 & All regions & $<70$ & $\begin{array}{l}M: 6.0-8.6 \\
M_{1}: 4.9-7.7 \\
M-M_{1}: 0.2-2.3\end{array}$ & \\
\hline
\end{tabular}


and Palisades, separately. In our bulletins, we report the average $M$ for Uppsala and Kiruna, and for this average the standard deviation is calculated as follows:

$$
D_{M}= \pm\left[\Sigma\left(M_{Z}-M\right)^{2} /(N-2)\right]^{1 / 2}
$$

where

$$
\begin{aligned}
M_{Z}-M & =\frac{1}{2}\left[a \log \left(A_{Z} / T_{Z}\right)+b-\log \left(A_{I I} / T_{H}\right)\right]_{\mathrm{UPP}}+ \\
& +\frac{1}{2}\left[a \log \left(A_{Z} / T_{Z}\right)+b-\log \left(A_{n} / T_{H}\right)\right]_{\mathrm{KIR}}
\end{aligned}
$$

We find $D_{M}= \pm 0.11(N=252)$, which means that the fit of the vertical components to the horizontal ones has been made with a deviation well within errors of any sing.e magnitude calculation.

The resulting vertical-component magnitude formulas become:

Uppsala: $\quad M=\log \left(A_{Z} / T_{7}\right)+1.66 \log \Delta+3.2$

Kiruna: $\quad M=\log \left(A_{Z} / T_{Z}\right)+1.66 \log \Delta+3.5$

Palisades: $\quad M=\log \left(A_{Z} / T_{Z}\right)+1.66 \log \Delta+3.3$.

Two conclusions are obvious from these results:

(1) The pasadena result (ath, 1952) with $a \neq 1$ in equation [13] is not confirmed. The present result appears more agreeable also from a theoretical viewpoint.

(2) Formulas for $M$ from the vertical component can be written as for the horizontal component, equation [2], and the deviation can be introduced as a station correction. As the ratio of the vertical to the horizontal component depends on the structural layering around the station, this is a correct procedure also theoretically. A further refinement could be to express this station correction as a function of wave period and of azimuth, considering structural variations with depth and azimuth. However, this proves superfluous, considering the small deviations already achieved.

Focal depth corrections of $M$ (Section 5) are assumed to be the same as for the horizontal component. 
7. RELATIONS BETWEEN $m$ AND $m$ (US).

Although the type of short-period seismograph to be used in calculating $m$ is not stated in the Zurich recommendations, it soon became clear that there are significant differences in $m$ from narrow-band instruments, like Benioff, compared to even slightly more broad-banded seismographs, like Grenet. In our bulletins, $m$ from Uppsala and Kiruna is based on Grenet instruments. On the other hand, $m$ (US), closely agreeing with $m$ (ISC), is based on Benioff instruments. As both magnitudes are in current use, it appears desirable to have clear relations between the two.

Regressions $m \rightarrow m$ (US) and $m$ (US) $\rightarrow m$ as well as major axis solutions $m \leftrightarrow m$ (US) have been derived using the same material as in Table 1, but this time including earthquakes of any depth, as the relations between $m$ and $m$ (US) are expected to be depth-independent. The results are summarized in Table 6.

As in Section 4 , it is found that the parameters $a$ and $b, a^{\prime}$ and $b^{\prime}$ are strongly correlated to each other, as evidenced by the results summarized in Table 3. Again, we are therefore in a possibility to replace the two parameters by just one parameter in each case, as given in the last column of Table 3. As in Section 4, these results imply that the straight lines in each group intersect in nearly one and the same point, but have different slopes. As in Section 4, we also find that the results in terms of $m$ and $m$ (US), respectively, generally agree between regions, at least in the central parts of the point clouds, but that the parameters $a$ and $b^{\prime}, a^{\prime}$ and $b^{\prime}$ show significant deviations between regions. On the other hand, there are no relations between $a, b, a^{\prime}, b^{\prime}$ for $m-m$ (US) and those for $m-M$ (Section 4), which means that the underlying factors are different in the two cases.

The significant difference between $m$ and $m$ (US) makes it necessary tc specify in each case (bulletins, publications, etc.) which kind of $m$ is used or which type of instruments is used. Judging from the worldwide relation between $m$ and $M$, equation [8], it is suggested that $m$ is in better agreement with the definition of Gutenberg and Richter (1956) than is $m$ (US) or $m$ (ISC).

It is instructive to compare the different standard deviations for the $m-M$ relations (Table 2) and the $m-m$ (US) relations (Table 6 ). Due to the larger slope of the point clouds in the latter case, with $a$ 
TA 3LE 6 .

\begin{tabular}{|c|c|c|c|c|c|c|c|c|c|c|c|c|c|}
\hline \multicolumn{14}{|c|}{ Relations be:ween $m$ and $m$ (US) for all $h$. } \\
\hline \multirow{2}{*}{$\begin{array}{l}\text { Earthquake } \\
\text { region }\end{array}$} & \multicolumn{6}{|c|}{ Reg tessions } & \multicolumn{7}{|c|}{ Major axis solutions } \\
\hline & $\begin{array}{l}m= \\
a\end{array}$ & $m=a m(\mathrm{US})+b$ & $\begin{array}{l}+b \\
-D_{n} \\
\end{array}$ & \multicolumn{3}{|c|}{$m(\mathrm{US})=a^{\prime} m+\overline{b^{\prime}}$} & $a^{m}$ & $m=a m(\mathrm{US})+b$ & $\begin{array}{l}+b \\
\pm D_{n}\end{array}$ & \multicolumn{3}{|c|}{$m(\mathrm{US})=a^{\prime} m+b^{\prime}$} & $\pm D$ \\
\hline 1 & 0.73 & 2.18 & 0.25 & 0.47 & 2.69 & 0.21 & 1.44 & -1.84 & 0.33 & 0.70 & 1.28 & 023 & 0.19 \\
\hline 2 & 0.92 & 1.15 & 0.23 & 0.73 & 1.03 & 0.20 & 1.15 & -0.17 & 0.24 & 0.87 & 0.15 & 0.21 & 0.16 \\
\hline 3 & 0.98 & 0.57 & 0.20 & 0.82 & 0.61 & 0.18 & 1.10 & -0.07 & 0.20 & 0.91 & 0.05 & 0.18 & 0.13 \\
\hline 4 & 0.98 & 0.74 & 0.23 & 0.69 & 1.33 & 0.19 & 1.25 & -0.74 & 0.24 & 0.80 & $0.5 \hat{9}$ & 0.19 & 0.15 \\
\hline 5 & 0.53 & 327 & 0.29 & 0.53 & 2.37 & 0.29 & 1.02 & 0.53 & 0.34 & 0.99 & -0.53 & 0.32 & 0.23 \\
\hline 6 & 0.99 & 1.00 & 0.23 & 0.70 & 1.02 & 0.19 & 1.24 & -0.35 & 0.24 & 0.81 & 0.29 & 0.19 & 0.15 \\
\hline 7 & 0.92 & 1.16 & 0.27 & 0.61 & 1.77 & 0.23 & 1.31 & -1.05 & 0.31 & 0.76 & 080 & 0.24 & 0.19 \\
\hline 8 & 0.85 & 1.57 & 029 & 0.68 & 1.41 & 0.26 & 1.15 & -0.23 & 0.32 & 0.87 & 020 & 0.27 & 020 \\
\hline 9 & 0.94 & 0.94 & 0.22 & 0.73 & 1.08 & 0.20 & 1.17 & -0.33 & 0.24 & 0.85 & 0.28 & 0.21 & 0.16 \\
\hline 10 & 1.05 & 0.28 & 0.27 & 0.61 & 1.69 & 0.21 & 1.40 & -1.53 & 0.30 & 0.71 & 1.09 & 0.22 & 0.18 \\
\hline 11 & 0.85 & 1.44 & 0.25 & 0.73 & 1.08 & 0.24 & 1.10 & 0.03 & 0.27 & 0.91 & -0.03 & 024 & 0.18 \\
\hline 12 & 0.98 & 0.53 & 0.36 & 0.55 & 2.18 & 0.28 & 1.48 & -2.13 & 0.42 & 0.68 & 1.44 & 0.28 & 0.23 \\
\hline Total & 0.95 & 0.93 & 0.28 & 0.67 & 1.41 & 024 & 1.24 & -0.70 & 0.31 & 0.81 & 0.57 & 0.25 & 0.19 \\
\hline $\begin{array}{l}\text { Nuciear } \\
\text { crp'osions }\end{array}$ & 0.39 & 4.22 & 0.20 & 0.74 & 1.32 & 0.28 & 0.57 & 3.13 & 0.21 & 1.76 & -5.50 & 0.37 & 0.18 \\
\hline
\end{tabular}


approximating $155^{\circ}$, all four standard deviations $D_{m}$ and $D_{m \text { (US) are }}$ approximately equal. But in the $m-M$ case, the slopes are smaller with the consequence that $D_{M}>D_{m}$ both for regressions and for major axis sclutions. Comparing the two latter, we find that $D_{M}$ is about equal but that $D_{M}$ is larger for the major axis solutions than for the regressions. Proceeding into more detail and comparing the different regions, we find similar relations between standard deviations and point cloud slopes. Estimating the average deviation of any single magnitude determination as around \pm 0.3 units, we find that all $D$ are within or equal to this limit, except $D_{\mathbb{W}}$.

While $m$ is derived from records at UPP and KIR, $m(U S)$ is based on a number of various stations reporting to NEIS. Therefore, it would appear desirable to have not only $m$ but also $m$ (US) under more direct control. For this purpose, we operated at Umea (UME) for a few months in 1966 a Grenet seismograph side by side with the Benioff instruments. With the material as specified in Table 5, measurements on the two instruments could be related to each other, with the following regressions as result:

$$
\begin{aligned}
& \log (A / T)_{B}=0.96 \log (A / T)_{G}-0.47 \pm 0.05 \\
& \log (A / T)_{G}=1.03 \log (A / T)_{B}+0.47 \pm 0.05 .
\end{aligned}
$$

The corresponding relation between the magnitudes is thus:

$$
m_{G}-m_{B}=0.47 \pm 0.05
$$

with sufficient accuracy. This means that there is a constant difference between these two magnitudes. Similar results are also found from parallel recordings at Uppsala.

Identifying $m_{G}$ with our $m$, and $m_{B}$ with $m$ (US), we find approximate agrecment with results in Table 6 only for the major axis solutions for Region 5 and the regression $m \rightarrow m$ (US) for Region 12. But a significant difference is that the correlation between our $G$ and $B$ is much strenger, with considerably smaller standard deviation in the results. We have anticipated the differences between $G$ and $B$ to be due to different bandwidths of their rseponse curves. Even though this is at least a partial explanation, it is possibly not the whole explanation. 
Partly do the response curves for $G$ and $B$ not deviate considerably from each other, partly are the recorded periods identical in all the 159 cases investigated at Umeâ. Other instrumental differences, not fully clarified, may contribute to the difference.

\section{UNDERGROUN NUCLEAR EXPLOSIONS.}

Magnitudes have found extensive application in explaining dynamic properties of seismic events. We snall illustrate this by two examples, in this and the following sections. Due to the special source mechanism of underground nuclear explosions, the relation between $m$ and $M$ is generally different from the relation for earthquakes (Section 4). For any given $M$, the corresponding $m$ is generally much higher for explosions than for earthquakes. In order to investigate the $m-M$ and $m-m$ (US) relations for explosions we collected material from the Uppsala seismological bulletins and from the Preliminary Determination of Epicenter monthly listing of NEIS (Table 5). The results are summarized on the bottom lines in Tables 2 and 6 . A certain trouble arises from the fact that in some instances the period or the distance is below the range stipulated for the Moscow-Prague $M$-formula, equation [2].

There are quite clear deviations between results for different shot locations. Fcr both the regressions $m \rightarrow M$ and $n \rightarrow m$ (US), the residuals $m_{0}--m_{c}$ are generally negative for Nevada, positive for Semipalatinsk and the Aleutians and around zero for Novaya Zemlya and the Caspian Sea area.

The relations between $m$ and $m$ (US) have remarkably different slopes compared to earthquakes, but they do not contribute anything to the discrimination prcblem. On the other hand, the relations between $m$ and $M$ are of interest for discrimination between underground explosions and earthquakes. Our results indicate that discrimination based on magnitudes is not so fully reliable as has sometimes been suspected in the past. Comparing the major axis solutions, as best representing the point clouds, we find, including the standard deviations, that separation is best for low magnitudes and can be trusted up to about $M=6.3$ for earthquakes with $h \leq 50 \mathrm{~km}$ but only up to $M=5.6$ for earthquakes of greater depth. This holds even though surface waves are usually more important in earthquakes of any depth than in explo- 
sions. Discrimination on this basis is generally more favourable for Semipalatinsk and the Aleutians than for Nevada. If instead of comparing major axes and respective standard deviations, we compare the point clouds directly, we find even worse results. The point clouds overlap partia!ly from $M$ about 5.5 and up, whence more reliable discrimination on the basis of magnitudes alone would be possible only for magnitudes below this value. This is an argument in favour of the installation of more high-sensitive long-period seismographs.

Another application of magnitudes to underground explosions is to calculate their yield. The needed information on yields for the derivation of such relations is available only for American shots (cf. Bolt, 1976). We find a good relation between our $m$ (average of Uppsala and Kiruna) and the yields $Y$ in kiloton for NTS shots (Table 5), as follows:

Correlation between $m$ and $\log Y=+0.95 \pm 0.03$

Regression $m \rightarrow Y: \quad m=0.53 \log Y+4.95 \pm 0.08$

Regression $Y \rightarrow m: \quad \log Y=1.70 m-8.20 \pm 0.16$

Major axis solution $m \leftrightarrow Y: \quad m=0.54 \log Y+4.92 \pm 0.08$

$$
\log Y=1.84 m-9.05 \pm 0.16
$$

Resulting $D= \pm 0.08$

The regression $Y \rightarrow m$ with a standard deviation of \pm 0.16 in $\log Y$, implies that $Y$ can be calculated with an error of 37 percent. This error compares favourably with results of spectral calculations, and in fact, by subdividing the $Y$-range, it is possible to decrease the error to 18 percent of the yield for $Y<200 \mathrm{kt}$ for NTS shots from magnitudes only. Tests on other explosions with approximately given yields, not used in deriving equations [20], give in general acceptable agreement. But this is true only for NTS shots. Caution is required in using these relations for other shot areas. For instance, shots in the Aleutians and probably also in the Semipalatinsk area give too high magnitudes at our stations. In other words, yields calculated from equation [20] by our magnitudes are too high. This depends probably on structural properties near the source, especially downgoing asthenospheric slab in case of the Aleutians and exceptionally good propagation properties in the Semipalatinsk case. 
The regression $m \rightarrow Y$, equation [20], permits an estimate of the seismic efficiency $\gamma$, i. e. the fraction of the explosive energy that is converted into seismic wave energy. From the $E-M$ relation (Bâth, 1958, 1966):

$$
\log E=12.24+1.44 M
$$

in combination with the world-wide major axis solution $m \leftrightarrow M$ for earthquakes (Table 2):

$$
M=1.80 m-5.29
$$

and the energy relation:

$$
E=4.2 \cdot 10^{19} \gamma Y
$$

we find:

$$
\gamma=Y^{0.4} / 180
$$

Numerical results are given in Table 7 . Values of $\gamma$ lie generally between $10^{-2}$ and $10^{-1}$ and exhibit a slight increase with increasing yield. This could be due to a positive correlation between yield and depth of explosion, the greater depths implying better seismic efficiency.

TABLE 7.

Seismic efficiency $\gamma$ of underground NTS explosions.

\begin{tabular}{rcc}
\hline $\begin{array}{c}\text { Yield } Y \\
k t\end{array}$ & $\begin{array}{c}\text { Depth } h \\
\mathrm{~m} \text { (approx.) }\end{array}$ & Efliciency $\gamma$ \\
\hline 100 & 600 & $3.6 \cdot 10^{-2}$ \\
300 & 800 & $5.8 \cdot 10^{-2}$ \\
500 & 900 & $7.1 \cdot 10^{-2}$ \\
700 & 1100 & $8.1 \cdot 10^{-2}$ \\
900 & 1300 & $8.9 \cdot 10^{-2}$ \\
1200 & 1500 & $10.5 \cdot 10^{-2}$ \\
\hline
\end{tabular}




\section{MAIN EARTHQUAKES AND L.ARGEST AFTERSHOCKS.}

A dynamic property of aftershcck sequences is that the difference in $M$ between the main shock and the largest aftershock averages 1.2 units (the so-called Bâth's law, cf. Richter, 1958, p. 69). In other words, there is a finite magnitude difference between these two events. When first formulated, it was based on relatively few sequences, but it has got additicnal confirmation in course of time and been studied by several authcrs both from statistical and physical sides. With the greater abundance of reliable magnitudes now available, it appears desirable to test this formula on a larger material.

From the Uppsala seismological bulletins, 116 aftershock sequences were listed (Table 5). The aftershocks have occurred within a few hours up to several months after their respective main earthquakes. Sometimes there may be twc or several main earthquakes of nearly equal magnitude, likewise there may be two or several about equally large aftershocks. In such cases the main earthquake is assigned a mannitude $M$ corresponding to the total energy release in all main earthquakes, and similarly the largest aftershock is assigned a magnitude corresponding to the total energy of these aftershocks, using equation [21] and following a principle suggested by Bâth (1965). If $M^{\prime}, M^{\prime \prime}, \ldots$ $\ldots,\left(M^{\prime} \geq M^{\prime \prime} \geq \ldots\right)$ is the sequence of nearly equally large main shocks (or aftershocks), then the magnitude for the main shock (or largest aftershock, respectively) is obtained from the following formula:

$$
M=M^{\prime}+\frac{1}{1.44} \log \left[1+10^{1.44\left(M^{\prime \prime}-M^{\prime}\right)}+\ldots\right]
$$

In spite of this procedure, it is unavoidable that some bias creeps into this work, as it is not always obvious if an earthquake is to be considered as a main earthquake or as an aftershock. Cases of more swarm-like characteristics have to be excluded. In a few cases, even large main shocks are not followed by any aftershocks recorded by our long-period seismographs, and these have naturally also to be excluded. Still, it is believed that such effects will have only a minor influence on the result.

As an average of all magnitude differences $M-M_{1}$ we find: 


$$
M-M_{1}=1.15 \pm 0.42
$$

which is in perfect agreement with the original formulation (Richter, 1958, p. 69). In combination with our $m \leftrightarrow M$ relation we then get the corresponding relation for $m$ :

$$
m-m_{1}=0.63
$$

Expressed in energy, this means that the energy of the largest aftershock is only about 2 percent of the energy of the main earthquake.

We have further investigated possible relations between $M-M_{1}$ and other parameters, with the following results.

(1) Magnitude $M$. Plotting $M-M_{1}$ versus $M$ we find in spite of large scatter some suggestion for a dependence of the type:

$$
M-M_{1}=0.28 M-0.93 \pm 0.40
$$

As seen, the standard deviation is practically as large as in equation [26] and no improvement in accuracy has been achieved.

(2) Epicentral region. Listing $M-M_{1}$ for different regions, as defined in Table 1, we find clear regional variations, as follows for regions with a sufficient number of observations:

$\begin{array}{rrlr}\text { Region } 3 & M-M_{1}=1.2 & \text { Normal } & N=13 \\ 4 & 1.2 & \text { Normal } & 19 \\ 5 & 0.8 & \text { Low } & 7 \\ 7 & 1.2 & \text { Normal } & 14 \\ 8 & 1.0 & \text { Normal } & 18 \\ 11 & 1.6 & \text { High } & 13 \\ \text { w Zeland } & 1.0 & \text { Normal } & 6 \\ & 0.9 & \text { Low } & 7\end{array}$

(3) Focal depth. Our present material has been restricted to $h \leq 70 \mathrm{~km}$, and within this depth range no dependence exists between $M-M_{1}$ and $h$. Observations are too scanty to deduce any relation between $M-M_{1}$ and $h$ for deeper events, even though a dependence is expected, as tentatively suggested by Bâth (1965).

Probably the most extensive use that magnitudes have found in 
earthquake statistics is represented by magnitude-frequency relations of the type:

$$
\log N=a-b M .
$$

Our bulletin material does not prove very suitable for this kind of study. As a world-wide average for $M=5.5-8.0$ and $h \leq 50 \mathrm{~km}$, we find the value of $b$ to be as low as around 0.7. It is not excluted that this may be influenced by a gradual tapering off of our material towards the lower magnitudes in the range studied.

10. Homogeneous magnitudes.

Complete magnitude formulas should include both source correction and station correction (cf. Batth, 1973, p. 110). Theoretically this is naturally a step in the right direction, i.e. to correct for radiation patterns from the source, for path properties and for receiver structural influences, etc. But in practice we are quite handicapped in determining reliable corrections because of the lack of acceptable reference magnitudes. Usually this is circumvented by using determinations at one or a $\mathrm{f} \in \mathrm{w}$ stations, considered to be reliable. However, even if they may be very reliable, their readings are also subjected to the same influences as at any other station. Such reductions can therefore hardly be considered to be more than a relative calibration.

One way to approach a solution of this problem would be to use a world-wide net of magnitude reference stations. I have earlier (Bâth, 1969 , p. 80) suggested such a world system of magnitude stations, numbering about 15, well located and well distributed around the earth. By an even distribution we would eliminate influences of source mechanism, path and station properties, which are unavoidable for individual stations, however good they may be.

Instead of forming a simple average magnitude from these stations, I like to discuss an alternative procedure. The underlying principle is to deduce a magnitude which corresponds to the energy radiated from the source. In other words, the adopted magnitude should correspond to the average energy. Due to the relation between $E$ and $M$, equation [21], the average energy is not equivalent to the average magnitude. 
The magnitude corresponding to the average energy is calculated from the following equation:

$$
M=\frac{1}{1.44} \log \left[\left(10^{1.4 H \prime}+10^{1 .+1 M^{\prime \prime}}+\ldots\right) / N\right]
$$

obtained by applying equation [21] and where $M^{\prime}, M^{\prime \prime}, \ldots$ are the individual station magnitudes. As an example, with only $N=2, M^{\prime}=6.5$, $M^{\prime \prime}=7.5$, the magnitude average is 7.0 , while the magnitude which corresponds to the average energy is 7.3 from equation [30]. The latter magnitude would then be considered more representative than the simple average.

Having this, other stations could calibrate their own magnitudes against this standard. Calibration for a sufficient number of earthquakes, well distributed around the earth, would permit calculation of a station correction. Then, a further improvement would be to calculate corrections for each seismic region separately, i. e. source corrections. The two corrections can naturally be combined into one value, for each region. Along these lines, magnitude residuals could be made equally unbiased as travel-time residuals. A related suggestion for the Eurasian region has been given by Christoskov et al. (1974).

Availability of homogeneous magnitudes would also assist considerably in further development of the formulas for $m$ and $M$ (Section 3), especially to bridge the gap between about $10^{\circ}$ to where local scales $\left(M_{L}\right)$ may be applicab!e, and the lower limits of $16^{\circ}$ and $20^{\circ}$ for $m$ and $M$, respectively.

\section{Conclusions.}

Main results of general validity can be summarized in the following points.

(1) Relations between body-wave magnitude $(m)$ and surfacewave magnitude $(M)$ depend on the earthquake region concerned and can be expressed in terms of one regional magnitude parameter.

(2) The focal deph correction to $M$ incereases from zero at $50 \mathrm{~km}$ depth to -0.4 at $100 \mathrm{~km}$ depth and after that it remains constant $=+0.4$ for all greater depths. 
(3) Surface-wave magnitudes $(M)$ can be calculated from the vertical component by the same formula as for the horizontal component, only by including a minor station correction.

(4) Body-wave magnitudes $(m)$ determined from broad-band short-period seismographs show consistent differences from those determined from narrow-band seismographs. This is illustrated by differences between Grenet and Benioff instruments.

(5) Relations between $m$ and $M$ for underground nuclear explosions demonstrate that discrimination from earthquakes on the basis of magnitudes alone is trustworthy only for $M$ less than about 5.5 to 6.0 .

(6) Relations between $m$ and the yield of underground nuclear explosions in Nevada suggest a seismic efficiency of the order of $10^{-2}$ to $10^{-1}$. increasing slightly with yield (or depth).

(7) Main earthquakes and largest aftershocks show an average difference of 1.15 in surface-wave magnitude $(M)$. The difference increases slightly with magnitude of the main shock, it also varies from region to region, but it is independent of focal depth at least down to $h=70 \mathrm{~km}$.

(8) A homogeneous world-wide network is suggested for estab!ishing more relable magnitudes, particularly for deducing corrections to individual station determinations and for further development of magnitude scales.

\section{REFERENCES}

Alsan, E., Tezuçan, L. and BAth, M., 1975. - An earthquake calaiogue for Turkey for the interval 1913-1970. "Seismol. Inst., Uppsala », Rep. No. 7-75, pp. 166.

BATH, M., 1952. - Earihquake magnitude determination from the vertical component of surface waves. "Trans. Am. Geophys. Un. », 33, p. 81.

BĀTH, M., 1956. - The problem of earthquake magnilude delermination. "Publ. Bur. Centr. Seism. Int. ", A 19, p. 5.

BÅTH, M., 1958. - The energies of seismic body waves and surface waves. "Contr. in Geophys. (Gutenberg Vol.) », 1, p. 1.

BÅTH, M., 1965. - Lateral inhomogeneities of the upper mantle. "Tectonophysics", 2, p. 485 . 
BÅTH. M., 1966. - Earthquake energy and magnitude. «Phys. and Chem. Earth.", 2. p. 115 .

P.̊̊г,. M., 1969. - Handbook on Earthquake Magnitude Determinations. « Seismol. Inst., Uppsala », pp. 158.

RÅTH, M., 1973. - Introduction to Seismology. Birkhäuser, Basel, pp. 395.

Bolt, B. A., 1976. - Nuclear Explosions and Earthquakes. Freeman, San Francisco, pp. 309.

BormanN, P. and Wylegalla, K., 1975. - Untersuchung der Korrelationsbeziehungen zwischen verschiedenen Arlen der Magnitudenbestimmung der Station Moxa in Abhängigkeit vom Geriletyp und vom Herdgebiet. «Publ. Inst. Geophys., Polish Acad. Sci. », 93, p. 159.

Bullen, K. E., 196j. - An Introduction to the Theory of Seismology. Cambridge Univ. Press, pp. 381.

Christoskov, L., Fejorova, I. V., Kondorskaya, N. V. and Vanek, J., 1974. - On a homogeneous system of selected Eurasian stations for magnitude determinations. "Pure Appl. Geophys.", 112, p. 619.

GutenizekG, B, and Richter, C. F., 1956. - Magnitude and energy of earthquakes. "Ann. Geolis. ", 9, p. 1.

Richter, C. F., 1958. - Elementary Seismology. Freeman, San Francisco, pp. 768.

Vaněk, J., Zntopek, A., Kárník, V., Kondorskaya, N. V., Riznichenko, Yu. V., SAvirensky, E. F., Solovyey, S. L. and Shebalin, N. V., 1962. - Siandrirdizalion of magnilude scales. "lzv. Akad Nauk SSR, Ser. Geofiz.", 2, 